\title{
Surface sterilization method for reducing contamination of Clinacanthus nutans nodal explants intended for in-vitro culture
}

\author{
Saiyidah Nafisah Hashim ${ }^{1}$, Siti Zulaiha Ghazali ${ }^{2}$, Norrizah Jaafar Sidik $^{3 *}$, Tay Chia-Chay ${ }^{3}$, \\ and Azani Saleh ${ }^{3}$ \\ ${ }^{1}$ Department of Biology, Faculty of Applied Sciences, Universiti Teknologi MARA, Perak Branch, \\ Tapah Campus, 35400 Tapah Road, Perak, Malaysia \\ ${ }^{2}$ Department of Biology, Faculty of Applied Sciences, Universiti Teknologi MARA Perlis, 03500 Arau, \\ Malaysia \\ ${ }^{3}$ Department of Biology, Faculty of Applied Sciences, Universiti Teknologi MARA Shah Alam, 40450 \\ Shah Alam, Selangor, Malaysia
}

\begin{abstract}
Surface sterilization is a vital step in preparation of healthy and viable explants in tissue culture. Most surface contaminants can be eliminated by surface sterilization with a suitable sterilizing agent. The study aimed to present an effective disinfection method for Clinacanthus nutans shoot regeneration using nodal segments. A total of four different sterilization approaches were conducted by treating nodal explants with various concentrations of sterilizing agent. Sterilizing agents used were Rhizophora apiculata Pyroligneous acid (PA), sodium hypochlorite (Clorox) thiophanate-methyl (fungicide), and Mercuric chloride $\left(\mathrm{HgCl}_{2}\right)$. Nodal explant then was cultured on plant growth regulator-free Murashige and Skoog (MS) basal medium. This study sterilizing agents revealed that PA showed strong bactericidal activity. However, it led to a high number of fungal contaminations. The pyroligneous acid did not exhibit a strong potential as a disinfectant for C. nutans nodal explant. Overall, $\mathrm{HgCl}_{2}$ exhibits the best reduction in fungal contamination and gives a significant result with thiophanate-methyl fungicide. Surface sterilization with mercuric chloride $(0.2 \%)$ for 1 hour was the optimum concentration and duration, which resulted in the highest percentage of nodal explant survival and viability. All viable nodal segments developed into shoots. It had been concluded that the best surface sterilization agent was $\mathrm{HgCl}_{2}$.
\end{abstract}

\section{Introduction}

C. nutans belong to the Acanthaceae family and is known as Sabah snake grass. It is a medicinal herb used to treat various diseases, such as skin rashes, insects, scorpion or snake

* Corresponding author: norri536@uitm.edu.my 
bites, diabetes, fever, diuretic, and gout. The plant has gained wide pharmaceutical applications such as cream, lotions, capsule tablets, herbal tea, and more [1]. Tissue culture technique is widely accepted in clonal propagation for large-scale medicinal and genetically improved plants $[2,3]$. Tissue culture-controlled growth environment conditions provide a proper supply of nutrients, $\mathrm{pH}$, temperature, gaseous and liquid environment [4]. In vitro, culture techniques are now used to propagate several plant species and are necessary for crop improvement [5].

However, in vitro cultures from the field-grown plant are prone to be infected by microorganisms. Plant culture contamination remains a persistent problem that can result in plant culture losses, not in a small number but a whole batch of cultures. Sterilization is crucial as the bacteria and fungi might contaminate the plant culture and continually threaten it during the culture period. Production of sterile and viable in vitro plantlets is crucial to increasing the clonal propagation efficacy in plant tissue culture [6]. It can be essential to use a proper and precise sterilization method in tissue culture techniques to save time and effort [7].

Optimization of sterilizing agent concentrations is an essential step to reduce contamination. A suitable concentration and duration of sterilizing agent exposure are crucial to raise in vitro culture success rate as the inappropriate concentration will restrict cell division and growth. Regardless of its profound health effect, mercuric chloride is frequently utilized for surface sterilization to reduce microbial contamination in a $C$. nutans tissue culture. Several studies have shown that mercuric chloride has several undesirable health effects, including neurological, renal, respiratory, immune, dermatological, reproductive, and developmental sequela $[8,9,10,11]$. $\mathrm{HgCl}_{2}$ is highly toxic to both plants and animals, and as it is difficult to dispose of the chemicals [12], a proper measure should be taken before its discard. While several adverse side effects have been reported, the use of it in plant sterilization is still significant and highlighted.

In monitoring fungal contamination rates for in vitro culture, common antifungal applied are Miconazole, PPM, Amphotericin B, Benomyl, Nystatin. Miconazole at concentrations ranged between 5 and $20 \mathrm{mg}^{-1}$ was sufficient to perform the best inhibition of hyphal growth and sporulation [13]. Bavistin is also one of the fungicides used to prevent contamination in tissue culture. However, the application had raised environmental concerns [14] and in terms of finding other alternatives and potential of other fungicide for sterililzation, the thiophanate-methyl fungicide was selected. Thiophanate-methyl (Thio-m) is a common agricultural chemical used to treat the plant anthracnose and fruit rot. This plant canker disease is ultimately lethal and therefore treating fungal becomes a top priority in agriculture and horticulture. The Thio-m fungicide had never been used in plant tissue culture sterilization before thus its potential as sterilizing agent at different concentrations was studied.

Pyroligneous extract of Rhizophora apiculata is a by-products from the wood-burning process in charcoal production and it is locally known as bakau minyak [15]. The smoke released from the charcoal kiln is directed into a long pipe and condensed. Afterward, the liquid is left to stand for natural purification in three months. Then three layers of liquid formed, with the top layer being the light oil, the middle is the raw PA (translucent brown color), and the bottom is the wood tar. Early evidence shows that the major groups of PA compounds are hydroxy aldehydes, hydroxy ketones, sugars, carboxylic acids, and phenolics [16]. It consists of 5.5\% acetic acid, 3.4\% methanol, and $6.5 \%$ wood tar. The PA is acidic ( $\mathrm{pH} 2-3$ ) and comprising with $8-10 \%$ volatile acids [17]. PA also contains small quantities of cadmium $(\mathrm{Cd})$, arsenic (As), and plumbum $(\mathrm{Pb})[18]$.

Studies were done on R. Apiculata pyroligneous acid from Matang, for its phenolic and antioxidant properties. The study shows that pyrolytic acid guarantees antibacterial efficacy, which is possibly why it is commonly used in traditional oriental medicine [19, 20,21]. PA 
is readily available, cheap, and found environmentally non-toxic The PA is well-described use in many applications, including fungicide, repellent, insecticide, herbicide, wood preservatives, plant growth enhancer, and feedstuff [22]. Overall, it is widely accepted that PA has outstanding potential for horticulture, agriculture, weed control, and forest conservation $[23,24,25]$. This study's objective was to evaluate effective sterilization protocol of $C$. nutans prior in vitro culture using different types of sterilizing agent.

\section{Materials and methods}

\subsection{Optimization of sterilization protocol}

Freshly harvested Clinacanthus nutans plant with 3-4 nodal from the shoot tip was collected and placed inside a beaker filled with tap water to keep the plant fresh. All the apparatus used for the sterilization process were thoroughly washed, and steam sterilized in an autoclave at a pressure of $1 \mathrm{~kg} / \mathrm{cm} 2$ at a temperature of $121^{\circ} \mathrm{C}$ for 15 minutes.

The plant was first washed under running tap water for 7 minutes to remove all surface residues for sterilization. The sample was then washed continuously with $10 \%$ sodium hypochlorite $(\mathrm{NaOCl})$ for 5 minutes and placed inside the laminar flow on a clean tissue paper. Using a sterile scalpel and forcep, the leaves were removed, and the nodal segments cut to $1-2 \mathrm{~cm}$ in size.

Table 1. Different sterilization treatments on nodal segments of C. nutans

\begin{tabular}{|c|c|c|c|}
\hline Sterilizing agent & $\begin{array}{c}\text { Sterilization } \\
\text { treatment code }\end{array}$ & Concentrations $(\%)$ & $\begin{array}{l}\text { Time of } \\
\text { exposure }\end{array}$ \\
\hline \multirow{3}{*}{$\begin{array}{c}\text { Sodium } \\
\text { hypochlorite }\end{array}$} & $\mathrm{B} 10$ & 10 & \multirow{3}{*}{10 minutes } \\
\hline & B20 & 20 & \\
\hline & B40 & 40 & \\
\hline \multirow{3}{*}{$\begin{array}{c}\text { Rhizophora } \\
\text { apiculate } \\
\text { Pyroligneous acid }\end{array}$} & PA10 & 10 & \multirow{3}{*}{7 minutes } \\
\hline & PA20 & 20 & \\
\hline & PA40 & 40 & \\
\hline \multirow{3}{*}{ Mercuric Chloride } & Hg0.1 & 0.1 & \multirow{3}{*}{1 hour } \\
\hline & $\mathrm{Hg} 0.2$ & 0.2 & \\
\hline & $\mathrm{Hg} 0.4$ & 0.4 & \\
\hline \multirow{3}{*}{$\begin{array}{c}\text { Thiophanate- } \\
\text { methyl }\end{array}$} & F10 & 10 & \multirow{3}{*}{30 minutes } \\
\hline & F30 & 30 & \\
\hline & F60 & 60 & \\
\hline
\end{tabular}

All cut nodal segments were selected as nodal explants and were exposed to different sterilizing agents to test the solution's effectiveness at varying concentrations and exposure time to reduce contamination. The first type of sterilizing agent used is mercuric chloride $\left(\mathrm{HgCl}_{2}\right)$, the second is sodium hypochlorite (Clorox), the third is thiophanate-methyl (fungicide), and the fourth is pyroligneous acid (Table 1). For $\mathrm{HgCl}_{2}$, nodal explant was soaked 30 minutes separately in the solution at three different concentrations of $0.1,0.2,0.4$ $\%$. The nodal explant was rinsed 3-4 times with sterile distilled water for about 10 minutes and then dried on sterile filter paper before culture on the Murashige and Skoog (MS) basal medium in the pillbox. The prepared MS basal medium is supplemented with $3 \%$ sucrose, agar, $\mathrm{pH}$ at 5.8 and then autoclaved.

The steps were repeated with sodium hypochlorite at three concentrations of 10, 20, 40 $\%$ for 10 minutes of soaking time, Thio-m at three concentrations of $10,30,60 \%$ for 30 minutes, and PA at three concentrations of 10, 20, $40 \%$ for 7 minutes. The plant cultures were maintained in a growth incubator at $25 \pm 1^{\circ} \mathrm{C}$, with 16 hours of light and 8 hours dark 
photoperiod. Percentage of contamination, aseptic, and viability were observed and made within four weeks of inoculation. Each treatment was assigned to 10 nodal explants with two explants per test tube and replicated three times.

\subsection{Statistical analysis}

The data was analyzed by the Analysis of variance (ANOVA) followed by Duncan's multiple range test. The significant difference among treatments was compared by critical difference. The data analysis was performed using SAS version 20.

\section{Results and discussions}

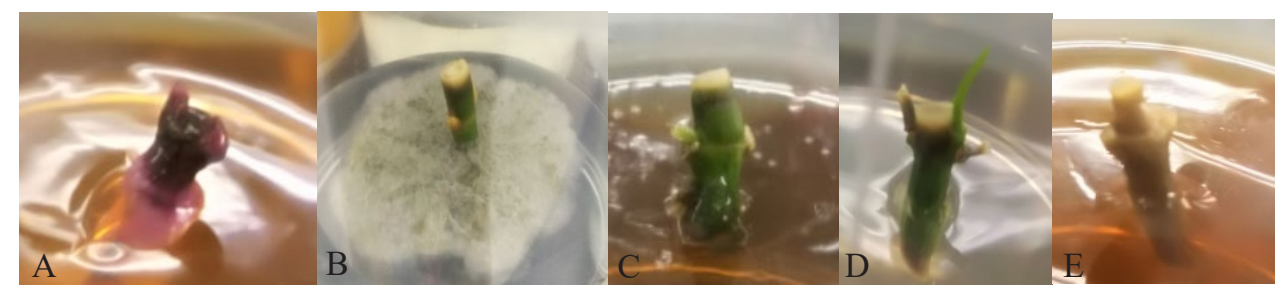

Fig. 1. Nodal explant conditions after sterilization treatments for in vitro culture establishment in $C$. nutans (A) nodal explant contaminated by bacteria (B) nodal explant contaminated by fungal (C) aseptic nodal explant (D) viable nodal explant (E) nodal explant undergo necrosis

In this study, the types of contamination were classified into two, bacteria and fungal contamination. Contamination was assessed visually by examining plants and growth media under fluorescent light. For early detection of bacteria contamination is often difficult, Izarra et al. [26] mentioned the bacteria contamination might only be marginally visible as a tiny faint halo around the base or roots of the in vitro plant. The bacteria do not grow well in tissue culture medium and may only be visible as a dark color of nodal explant.

In contrast, the fungal contamination is much easier to differentiate, based on visible spore-bearing structures or fruiting bodies surrounding the explant and growth medium (Fig. $1)$. The sterile or aseptic nodal was the explant free from any culture contamination. The viable explant is the aseptic explant which shows regeneration response. The percentage of contamination aseptic and viable explant was tabulated in Table 2.

Table 2. Results of sterilization treatment in Sodium hypochlorite, $\mathrm{PA}, \mathrm{HgCl}_{2}$ and Thio-m after 4 weeks

\begin{tabular}{|c|c|c|c|c|c|}
\hline \multirow{2}{*}{$\begin{array}{l}\text { Sterilization } \\
\text { treatment } \\
\text { code }\end{array}$} & \multirow[b]{2}{*}{$\begin{array}{l}\text { Sterilizing } \\
\text { agent }(\%)\end{array}$} & \multicolumn{2}{|c|}{ Contaminate } & \multirow[b]{2}{*}{$\begin{array}{c}\text { Aseptic } \\
(\%)\end{array}$} & \multirow[b]{2}{*}{$\begin{array}{c}\text { Viability } \\
(\%)\end{array}$} \\
\hline & & Bacteria $(\%)$ & $\begin{array}{c}\text { Fungal } \\
(\%)\end{array}$ & & \\
\hline B10 & $10 \% \mathrm{NaOCl}$ & $30.00^{d}$ & $33.33^{c}$ & $36.67^{\mathrm{e}}$ & $13.33^{f, g}$ \\
\hline $\mathrm{B} 20$ & $20 \% \mathrm{NaOCl}$ & $30.00^{\mathrm{d}}$ & $33.33^{\mathrm{c}}$ & $36.67^{\mathrm{e}}$ & $14.33^{f, g}$ \\
\hline B40 & $40 \% \mathrm{NaOCl}$ & $13.33^{b, c}$ & $36.67^{\mathrm{c}}$ & $50.00^{d}$ & $10.00^{\mathrm{f}, \mathrm{g}}$ \\
\hline PA10 & $10 \%$ PA & $23.33^{\mathrm{c}, \mathrm{d}}$ & $66.67^{\mathrm{e}}$ & $6.67 \mathrm{~g}$ & $3.33^{\mathrm{g}}$ \\
\hline PA20 & $20 \% \mathrm{PA}$ & $20.00^{\mathrm{b}, \mathrm{c}, \mathrm{d}}$ & $56.67^{\mathrm{d}}$ & $23.33^{f}$ & $13.33^{f, g}$ \\
\hline PA40 & $40 \% \mathrm{PA}$ & $10.00^{\mathrm{a}, \mathrm{b}}$ & $36.67^{\mathrm{c}}$ & $53.33^{d}$ & $26.67^{\mathrm{d}, \mathrm{e}}$ \\
\hline $\mathrm{Hg} 0.1$ & $0.1 \% \mathrm{HgCl}_{2}$ & $16.67^{b, c}$ & $0.00^{\mathrm{a}}$ & $83.33^{b}$ & $86.67^{a}$ \\
\hline $\mathrm{Hg} 0.2$ & $0.2 \% \mathrm{HgCl}_{2}$ & $3.33^{\mathrm{a}}$ & $0.00^{a}$ & $96.67^{a}$ & $96.67^{a}$ \\
\hline $\mathrm{Hg} 0.4$ & $0.4 \% \mathrm{HgCl}_{2}$ & $23.33^{\mathrm{c}, \mathrm{d}}$ & $0.00^{\mathrm{a}}$ & $76.67^{b}$ & $16.67^{\mathrm{e}}$ \\
\hline F10 & 10\% Thio-m & $23.33^{\mathrm{c}, \mathrm{d}}$ & $13.33^{b}$ & $63.33^{\mathrm{c}}$ & $46.67^{\mathrm{c}}$ \\
\hline F30 & $30 \%$ Thio-m & $16.67^{b, c}$ & $0.00^{\mathrm{a}}$ & $83.33^{b}$ & $66.67^{b}$ \\
\hline F60 & $60 \%$ Thio-m & $46.67^{\mathrm{e}}$ & $0.00^{\mathrm{a}}$ & $53.33^{d}$ & $33.33^{\mathrm{d}}$ \\
\hline
\end{tabular}




\subsection{Effect on different concentration of sodium hypochlorite on sterilization of C. nutans nodal explant}

Webster and Mitchell [27] stated acidified $\mathrm{NaOCl}(\mathrm{pH} 7)$ reduced both fungal and bacterial contamination. In sodium hyopochlorite solution, the amount of hypochloric acid ( $\mathrm{HOCl})$ and OCl-ion affect the bactericidal action [28,29]. Thus, it's necessary to find the optimum percent of $\mathrm{NaOCl}$ to use in the sterilization process. Referring to Table 2, there is no significant difference in all parameters studied with increasing the $\mathrm{NaOCl}$ concentration from 10 to $20 \%$. However, at the highest $\mathrm{NaOCl}$ concentration studied, $40 \% \mathrm{NaOCl}$ has increase the solution acidity. With $40 \% \mathrm{NaOCl}$ treatment has significantly reduced the bacteria contamination to $13.33 \%$ and increased the number of aseptic nodal explants to $50 \%$. However, the viable nodal explant tested from all this $\mathrm{NaOCl}$ treatment were only less than $15 \%$.

\subsection{Effect on different concentration of pyroligneous acid on sterilization of $C$. nutans nodal explant}

The nodal explant was subjected to PA at 10, 20, and 40\%. Results indicate that PA10 treatment shows a high number of contaminations with $66.67 \%$ and $23.33 \%$ of fungal and bacterial contaminations, respectively (Table 2). With an increment in PA concentration to $20 \%$, fungal contamination significantly reduces to $56.67 \%$. The treatment also shows a significant increase in the number of the aseptic explant with $13.33 \%$ viability. At the highest PA concentration tested (P40), the fungal and bacteria had successfully reduced with increment in the number of aseptic explants to $53.33 \%$ with $26.67 \%$ viability. The PA exhibited intense antibacterial activities [30] and possessed antifungal activity against plant pathogenic fungi [31,32]. According to Baimark et al. [33], wood vinegar's antifungal efficiency was reported to be intensely dependent on their phenolic compound contents.

PA40 shows a potential sterilizing agent for nodal explant sterilization in reducing contamination by fungal and bacteria; however, the concentration usage needs to be optimized to reduce the cause of toxicity towards the nodal explant. The non-viable of aseptic explant had developed necrotic symptoms and recorded dead. The death of nodal segments might attribute to the acidity or phytotoxicity of the PA solution towards explant. In ex vitro horticulture used, PA inhibited pathogens that could cause severe loss to crop [30]. This potential contributed by phenol and guaiacols of the PA as Huang et al. [34] also stated PA inhibited the causative agent for bacterial wilt on Ralstonia solanacearum. Ibrahim et al. [21] studied PA potential as antibacterial agent towards Bacillus subtilis (gram positive bacteria commonly found in soil) with the minimum inhibitory concentration (MIC) values between $1.56-3.12 \mathrm{mg} / \mathrm{mL}$ cells. A similar finding on the inhibitory effect of 6-10\% PA concentrations towards other microorganisms was documented by Mmojieje and Hornung [35] (Agrobacterium tumefacien and Xanthomonas campestris), Grewal et al. [36] (Pseudomonas sp.) and Mahmud et al. [37] (Corynebacterium agropyri).

\subsection{Effect on different concentration of mercuric chloride on sterilization of $C$. nutans nodal explant}

Low concentration of $\mathrm{HgCl}_{2}$ at $0.1,0.2$ and $0.4 \%$ was applied in this sterilization treatments. The result shows $\mathrm{HgCl}_{2}$ treatments had generated a significantly high percentage of aseptic nodal explants from $70-97 \%$. 0.1 and $0.2 \% \mathrm{HgCl}_{2}$ treatment shows significant reduced in both contaminations, with almost $100 \%$ produce viable, healthy nodal segments.

On the other hand, in $40 \% \mathrm{HgCl} 2$ treatments shows increment in the bacterial contamination percentage, and the explant viability were significantly reduced to $16.67 \%$ 
(Table 2). Observation showed that the nodal explant aseptic cultures became necrosis as it became browning, stopped them from growing further, and eventually dying (Fig.1). Too much exposure to $\mathrm{HgCl}_{2}$ causes toxicity to the explant. Thus, it is vital to identify a proper concentration of sterilizing agent $\mathrm{HgCl}_{2}$ as it is toxic to the plant tissues [7]. Previous studies reported surface sterilization on Cestrum nocturnum L [7] Pinelliaternata (Thunb.) Breit, [38] and field-grown strawberry explants [39] using $\mathrm{HgCl}_{2}$ at minimum concentrations of $0.05 \% \mathrm{w} / \mathrm{v}$ within several minutes showed $90-100 \%$ in terms of survival of explants. This study finding in accordance with published studies that $\mathrm{HgCl}_{2}$ was a better sterilizing agent and at $0.2 \% \mathrm{HgCl}_{2}$, gives the best sterilization effect among other sterilizing agents used to sterilize $C$. nutans nodal segments.

\subsection{Effect on different concentration of thiophanate-methyl on sterilization of C. nutans nodal explant}

The thiophanate-methyl (Thio-m) fungicide is commonly used in a field-grown plant and is known as a systemic fungicide (absorbed into the plant and moves from one plant organ, especially leaves, to other leaves). Webster and Mitchell [29] stated that a systemic fungicide might have decreased any such internal fungal contamination, and it circulates through the plant to control disease; thus, the plant could actively grow.

Referring to the data, Thio-m application for explant sterilization was also relevant. At 10 and $30 \%$ of Thio-m, the percentage of aseptic explants was $63.33 \%$ and $83.33 \%$, respectively. At F30, the percentage viability shows no significant difference with $0.1 \%$, and the treatment produces high plant viability at $66.67 \%$. Similar trends with $\mathrm{HgCl}_{2}$, increase in the Thio-m concentration during sterilization causes bacteria contamination that contributes to a reduction in the number of aseptic explants. An increase in this Thio-m concentration does not affect bacterial growth and decreases the explant's viability.

\subsection{Effect of different sterilizing agents and their different concentration on the level of microbial and fungal contamination}

PA is weak sterilizing agent gives the highest fungal contamination (20\% PA). Next, the second highest of fungal contamination was found in all sodium hypochlorite treatments, followed by Thio-m fungicide. There was no fungal contamination on $\mathrm{HgCl}_{2}$ treatments. Hence, the Thio-m and $\mathrm{HgCl}_{2}$ were both suitable to inhibit fungal growth in the sterilization of $C$. nutans. To range them from the best fungicide to the least: $\mathrm{HgCl}_{2}>$ Thio-m $>\mathrm{NaOCl}$ $>\mathrm{PA}$

Bacterial contamination was found significantly highest (46.67\%) in treatment with $60 \%$ Thio-m. High bacterial contaminations also were found in $\mathrm{NaOCl}$ treatment of $10 \%$ and $20 \%$ $\mathrm{NaOCl}$. By increasing the concentration of $\mathrm{NaOCl}$ treatment, the bacterial contamination was significantly reduced to $13.33 \%$. Nevertheless, PA showed satisfactory results with a slightly lower number $(10 \%)$ of bacterial contamination at the highest tested PA concentration. However, the study verified that surface sterilization with treatment of $0.2 \% \mathrm{HgCl}_{2}$ is optimal for $C$. nutans nodal decontamination as it gives the significant lowest in the bacterial contamination (3.33\%). Hence, the PA and $\mathrm{HgCl}_{2}$ were both suitable to inhibit bacterial contamination in the sterilization of $C$. nutans. To range them from the best bactericidal to the least: $\mathrm{HgCl}_{2}>\mathrm{PA}>\mathrm{NaOCl}>$ Thio-m. As it is important to assess the plant cleanliness and survivability, thus to range the sterilant from the best sterilant in produce aseptic explant: $\mathrm{HgCl}_{2}>$ Thio-m $>\mathrm{NaOCl}>\mathrm{PA}$. On the other hand, to range the sterilant from the best in produce viability explant: $\mathrm{HgCl}_{2}>$ Thio-m $>\mathrm{PA}>\mathrm{NaOCl}$. 


\section{Conclusion}

Various sterilization treatments yielded aseptic cultures but three highest aseptic culture percentage were achieved by treating the explants with $0.2 \%, 0.1 \% \mathrm{HgCl}_{2}$ for 1 hour and $30 \%$ thiophanate-methyl for 30 minutes. The maximum percentage of explant viability was achieved when explants were surface sterilized with $0.2 \%$ mercuric chloride. The use of Thio-m (30\%) gave high aseptic cultures but resulted in high necrotic cultures. So it is concluded from the above study that sterilization treatment of $0.2 \% \mathrm{HgCl}_{2}$ is effective for disinfecting C. nutans nodal explants intended for in vitro culture. This treatment resulted in maximum percentage of explant survival.

The authors would like to thank the Ministry of Higher Education, Malaysia, for financing the research under fund FRGS 5/3(102/2019). We are most grateful to the Faculty of Applied Sciences, UiTM Perak branch, Tapah campus, for laboratory and facilities support.

\section{References}

1. A. Alam, S. Ferdosh, K. Ghafoor, A. Hakim, A. Shukor, Juraimi, A. Khatib, Z.I. Sarker, Asian Pac. J. Trop. Med. 9, 4 (2016)

2. S. Zhang, N. Liu, A. Sheng, G. Ma, G. Wu, Sci. Hortic. 130, 4 (2011)

3. R. Singh, Tissue culture studies of sugarcane (Thapar Institute of Engineering and Technology, Patiala, India, 2003)

4. N. Panche, A. D. Diwan, S. R. Chandra, J. Nutr. Sci. 5 (2016)

5. O. Olowe, A. Adesoye, O. Ojobo, O. Amusa, S. Liamngee, J. Nat. Sci. Res. 4, 2 (2014)

6. M. Tilahun, D. Mulugeta, S. Manju, African J. Biotechnol. 12, 44, 6282-6286 (2013)

7. S. N. Mahmoud, N. K. Al-ani, Int. J. Res. Stud. Biosci. 4, 1, 4-9 (2016)

8. J. F. Risher, S. N. Amler, Neurotoxicology. 26, 4, 691-699 (2005)

9. WHO, Mercury in Drinking-water, (2005)

10. M. K. Sharma, A. Sharma, A. Kumar, M. Kumar, Food Chem. Toxicol. 45, 12, 24122419 (2007)

11. D. Durak, S. Kalender, F. G. Uzun, F. Demir, Y. Kalender, African J. Biotechnol. 9, 4, 488-495 (2010)

12. P. E. Akin-Idowu, D. O. Ibitoye, O. T. Ademoyegun, African J. Biotechnol. 8, 16, 37823788 (2009)

13. F. Altan, B. Bürün, N. Şahin, African J. Biotechnol. 9, 7, 991-995 (2010)

14. K. Rawal, H. Keharia, Plant Tissue Cult. Biotechnol. 29, 1, 111-119 (2019)

15. Y. Loo, K. Jain, I. Darah, Food Chem. 104, 1, 300-307 (2007)

16. D. Mohan, C. U. Pittman, P. H. Steele, Energy and Fuels. 20, 3, 848-889 (2006)

17. D. Ibrahim, J. Kassim, L. Sheh-Hong, and W. Rusli, J. Appl. Pharm. Sci. 3, 7, 7-13 (2013)

18. Zulkarami, M. Ashrafuzzaman, M. O. Husni, I. Mohd. Razi, Aust. J. Crop Sci. 5, 12, 1508-1514 (2011)

19. J.S.Kim, J.C. Kim, J.S. Choi, T.J. Kim, S. Kim, K.Y. Cho, Korean J Weed Sci. 21, 357$364(2001)$

20. P. Cheol, C.H. Hyun, L.W. Ho, C.B. Tae, L.Y. Tae, K. G. Cheol, Koren J Orient. Med. 17, 85-90 (2003)

21. D. Ibrahim, J. Kassim, S.H. Lim, W. Rusli, Malays. J. Microbiol. 10, 3 (2014)

22. K. Tiilikkala, L. Fagernäs, J. Tiilikkala, Open Agric. J. 4, 1, 111-118 (2014)

23. S. Roche, J. M. Koch, K. W. Dixon, Restor. Ecol. 5, 3, 191-203 (1997)

24. Boucher, M. Meets, South African J. Bot. 70, 2, 313-318 (2004)

25. M. E. Light, J. Van Staden, South African J. Bot. 70, 1, 97-101 (2004) 
26. M. L. Izarra, A.L. Panta, C.R. Maza, B.C. Zea, J. Cruzado, L.R. Gutarra, C.R. Rivera, D. Elis, J.F. Kreuze, Front. Plant Sci. 11, 903, (2020)

27. S. Webster, S. Mitchell, Vitr. Cell. Dev. Biol. Plant. November, 1-8 (2003)

28. E.F. George, Plant propagation by tissue culture, Part 1: The technology (No. Ed. 2). Exegetics limited (1993)

29. S. Govindaraju, P. I. Arulselvi, J. Saudi Soc. Agric. Sci. 17, 4, 435-444 (2018)

30. Y. Chalermsan and S. Peerapan, Asian J Food Agro Ind. 2, 189-195 (2009)

31. K.H. Jung, Biotechnol Bioprocess Eng. 12, 318-322 (2007)

32. H. A. Oramahi, T. Yoshimura, J. Wood Sci. 59, 4, 344-350 (2013)

33. Y. Baimark, J. Threeprom, N. Dumrongcha, Y. Srisuwan, N. Kotsaeng, J. Environ. Sci. Technol. 1, 4, 157-163 (2008)

34. Y.H. Huang, Y.I. Matsushita, K. Sugamoto, T. Matsui, J. Microbiol Biotechnol. 15, 1106-1109 (2005)

35. J. Mmojieje, A. Hornung, J. Crop Improv. 29, 2, 228-246 (2015)

36. Grewal, L. Abbey, L. R. Gunupuru, J. Anal. Appl. Pyrolysis. 135, 152-159 (2018)

37. K. N. Mahmud, M. Yahayu, S.T. MD Sarip, N.H. Rizan, C.B, Min, N.F. Mustafa, S. Ngadiran, S. Ujang, Z.A. Zakaria, Sains Malaysiana. 45, 10, 1423-1434 (2016)

38. Y. Zhan. J.F. Chen, A.A. Malik, Acta Hortic. Sin. 36, 2 (2009)

39. Jan, K. M. Bhat, M. A. Mir, M. A. Bhat, I. A. Wani, African J. Biotechnol. 12, 39, 57495753 (2013) 